\title{
PEMBELAJARAN MATEMATIKA TERAPAN DENGAN MODEL PETRI NET DAN MATRIKS
}

\author{
Ruvita Iffahtur Pertiwi \\ Universitas Wisnuwardhana Malang \\ e-mail: ruvitapertiwi@gmail.com
}

\begin{abstract}
Abstrak
Penelitian ini bertujuan untuk mengetahui model petri net dan matriks dari suatu permasalahan yang ada disekitar kita. Salah satunya adalah masalah antrian. Kita dapat memanfaatkan pembelajaran matematika untuk membuat model sistemnya. Petri net merupakan salah satu alat untuk memodelkan suatu permasalahan ke dalam bentuk diskrit. Selanjutnya, dapat diperoleh matriks dari model petri net tersebut untuk mengetahui keadaan selanjutnya. Penelitian ini menggunakan metode deskriptif kuantitatif dan desain petri net menggunakan software PIPE v.4.3.0. Pada penelitian ini dibuat model Petri net sistem pelayanan IGD RSUD Kota X dan menghasilkan model Perti net yang terdiri dari 15 place dan 17 transisi. Hasil representasi matriks forward incidence, matriks backward incidence, dan matriks incidence yang terbentuk memiliki banyaknya baris 15 dan banyaknya kolom 17 .

Kata Kunci: Matematika Terapan, Petri net, Antrian, Matriks

Abstract

This study aimed at specifying the model of petri net and matrix of existing problems around us. One of them is the queue problem. We can utilise mathematics learning to create a model system. Petri net is on of the tool to model a problem in a discrete form. Furthermore, a matrix of the petri net model can be obtained to estimate the next situation. This research used quantitative descriptive method and petri net design using PIPE v.4.3.0 software. In this study Petri net model made by City X Public Hospital ED system and produced the Perti net model consisting of 15 places and 17 transitions. The results of the forward incidence matrix representation, the backward incidence matrix and the incidence matrix are formed with the number of rows 15 and the number of columns 17.
\end{abstract}

Keywords: Applied Mathematics, Petri net, Queue, Matrix

\section{PENDAHULUAN}

Pembelajaran matematika dapat dilakukan dimana saja. Sering kali masyarakat hanya mengetahui matematika digunakan untuk menghitung saja, padahal banyak sekali manfaat dari ilmu matematika yang bisa kita pakai. Matematika dapat digunakan sebagai alat untuk menyelesaikan suatu permasalahan. Antrian merupakan salah satu masalah sistem event diskrit yang sering dijumpai di dalam kehidupan sehari-hari (Pertiwi, 2016 \& Winarni, 2011). Salah satu contohnya adalah antrian pelayanan kesehatan Antrian pelayanan di rumah sakit terjadi karena pasien harus melalui beberapa prosedur dan sistem pelayanan yang berlaku di rumah sakit yang dituju, dimana terkadang pasien yang datang 
lebih banyak jumlahnya dibandingkan dengan fasilitas layanan yang tersedia, sehingga antrian bisa terjadi (Mustofani, 2018).. Jika pasien dalam keadaan kritis atau gawat, maka pasien dapat masuk ke Instalasi Gawat Darurat (IGD). Pasien yang datang ke rumah sakit sangat membutuhkan pelayanan yang sangat cepat dan tepat, khususnya pasien dalam keadaan luka parah ataupun kritis pasti membutuhkan pelayanan yang cepat agar pasien dapat segera mendapat perawatan oleh dokter di IGD.

Sistem antrian merupakan salah satu perilaku sistem event diskrit. Sistem event diskrit adalah sistem dimana variabel-variabelnya dapat dihitung pada saat tertentu. Pada penelitian ini alat yang digunakan untuk memodelkan sistem adalah Petri net (Subiono \& Nurwan, 2014). Perkembangan Petri net pada awal tahun 1960an oleh C. A. Petri. Menurut Cassandras \& Lafortune (2008) Petri net merupakan graf bipartisi yang terdiri dari dua himpunan $\mathrm{P}$ (place) dan $\mathrm{T}$ (transisi). Penelitian ini akan membahas tentang model sistem antrian sistem pelayanan IGD RSUD Kota X. Model sistem antrian tersebut dikontruksi dan disimulasikan menggunakan Petri net.

Suatu Petri Net adalah suatu graf bipartisi, yang terdiri dari dua himpunan bagian $\mathrm{P}$ dan T, masing-masing menyatakan place dan transisi (Subiono, 2015). Petri Net merupakan tools Pemodelan yang mudah diaplikasikan untuk banyak sistem. Suatu kejadian dapat terjadi apabila beberapa keadaan telah terpenuhi. Informasi mengenai event dan keadaan ini masing-masing dinyatakan dengan transisi dan place. Place dapat berfungsi sebagai input menyatakan keadaan yang harus dipenuhi agar transisi dapat terjadi. Setelah transisi terjadi maka keadaan akan berubah dengan place yang menyatakan keadaan tersebut adalah sebagai output dari transisi.

Definisi 1. (casandras, 1993) petri net dinotasikan (P, T,A,w) dengan

$P$ : himpunan berhingga place, $P=\{p 1, p 2, \ldots, p n\}$,

$T$ : himpunan berhingga transisi, $T=\{t 1, t 2, \ldots, t m\}$,

$A$ : himpunan arc, $A \subseteq(P \times T) \cup(T \times P)$,

$w:$ fungsi bobot, $w: A \rightarrow\{1,2,3, \ldots\}$.

Petri net merupakan suatu graph berarah yang memiliki simpul (node) dari graph berupa place $\mathrm{P}$ dan arc (arah) transisi yang diambil dari himpunan transisi T. Petri net graph juga memiliki struktur multigraph yang menggunakan beberapa arc untuk menghubungkan dua simpul (node) atau ekivalen dengan memberikan bobot ke setiap arc yang menyatakan banyaknya jumlah arc (Komsiyah, 2012). Dalam notasi matematika penanda (marking) $x$ pada Petri net bertanda $(P, T, A, W)$ adalah fungsi $x: P \rightarrow N=\{0,1,2,3, \ldots\}$. Penanda dinyatakan dengan vektor kolom yang elemen-elemennya merupakan bilangan bulat tak negatif (banyaknya token dalam suatu place), yaitu $x=\left[x\left(p_{1}\right), x\left(p_{2}\right), \ldots, x\left(p_{n}\right)\right]^{T}$. Banyaknya elemen x sama dengan banyaknya place dalam suatu Petri net. Elemen ke-i 
pada vektor ini merupakan banyaknya token pada place $p_{i}$, dengan $x\left(p_{i}\right) \in\{0,1,2, \ldots\}$. Suatu transisi $t_{j} \in T$ dalam sebuah Petri net dikatakan kondisinya terpenuhi (enabled) jika $x\left(p_{-} i\right) \geq w\left(p_{i}, t_{j}\right)$ untuk setiap $p_{i} \in I\left(t_{j}\right)$. Dengan kata lain, transisi $t_{j}$ dalam sebuah Petri net enabled apabila banyaknya token pada $p_{i}$ sekurang-kurangnya sama dengan bobot pada arc yang menghubungkan $p_{i}$ dengan $t_{j}$, untuk semua $p_{i}$ yang menjadi input dari transisi $t_{j}$ (Murata, 1989).

Mekanisme perubahan keadaan pada Petri Net ditandai dengan perpindahan tokentoken pada Petri net tersebut sehingga mengubah keadaan Petri net. Secara umum, sebuah transisi pada Petri net yang enabled, diistilahkan dengan dapat di-fire (firing diartikan dengan transisi di-fire). Fungsi perubahan keadaan pada Petri net ini merupakan perubahan keadaan Petri net sebelum dan sesudah suatu transisi di-fire (Subiono, 2015). Suatu fungsi perubahan keadaan pada sebuah Petri net $(P, T, A, w, x)$, yaitu $f: \mathbb{N}^{n} \times T \rightarrow \mathbb{N}^{n}$ terdefinisi sebagai transisi $t_{j} \in T$ jika dan hanya jika $x\left(p_{i}\right) \geq w\left(p_{i}, t_{j}\right)$ untuk semua $p_{i} \in I\left(t_{j}\right)$. Jika $f\left(x, t_{j}\right)$ terdefinisi, maka ditulis $x^{\prime}=f\left(x, t_{j}\right)$ dengan $x^{\prime}\left(p_{i}\right)=x\left(p_{i}\right)-w\left(p_{i}, t j\right)+$ $w\left(t_{j}, p_{i}\right), i=1,2, \ldots, n$, hanya transisi enabled yang dapat di-fire. Berkurangnya token pada place input disebabkan karena proses transisi difire token di place input berkurang sebanyak bobot arc yang menghubungkannya dengan transisi yang di-fire sedangkan token di place output bertambah sebanyak bobot arc yang menghubungkannya dengan transisi yang difire.

Penelitian ini akan menghasilkan model Petri net yang kemudian dapat direpresentasikan dalam bentuk matriks matriks forward incidence, matriks backward incidence, dan matriks incidence. Banyaknya baris dan kolom dari matriks-matriks tergantung dari banyaknya place dan transisi yang ada pada model Petri net. Penelitian ini dapat dikembangkan untuk memperoleh waktu tunggu dari permasalah antrian yang terjadi.

\section{METODE}

Data dikumpulkan melalui wawancara kepala perawat IGD RSUD Kota X dengan pertanyaan terbuka terkait alur pelayanan dan dikembangkan oleh peneliti. Penelitian ini bertujuan untuk mengetahui model petri net dan matriks dari suatu permasalahan sebagai contoh antrian pasien di IGD. Berdasarkan tujuan tersebut penelitian ini menggunakan metode deskriptif yaitu mendeskripsikan sistem pelayanan IGD dalam bentuk Petri net dan matriks. 


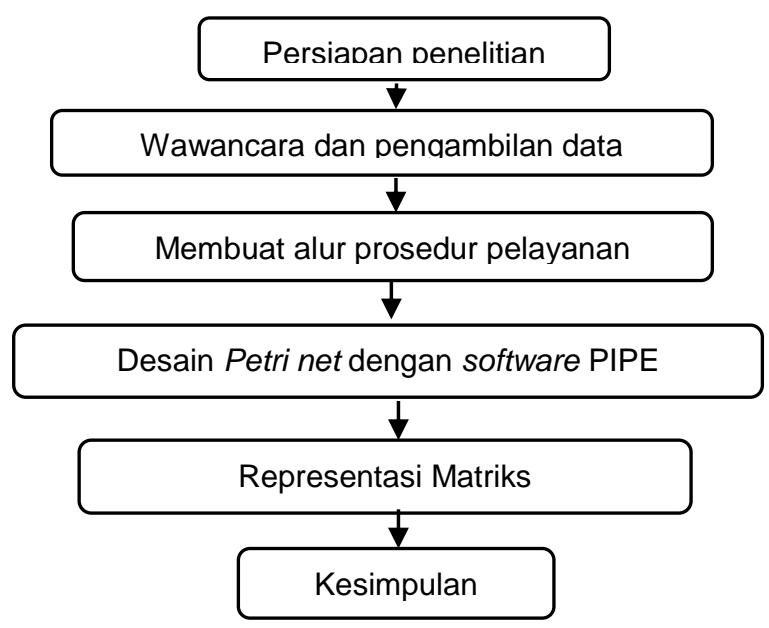

Gambar 1. Diagram Alir Penelitian

\section{HASIL DAN PEMBAHASAN}

Alur sistem pelayanan pasien IGD RSUD Kota $X$ dimulai dengan pasien datang hingga pasien pulang atau rawat inap. Pelayanan dimulai dari pasien datang ke tempat resepsionis, di bagian ini apabila pasien dalam keadaan yang sangat darurat tidak bisa mendaftar, keluarga atau kerabat pasien yang mendaftar pada bagian resepsionis.

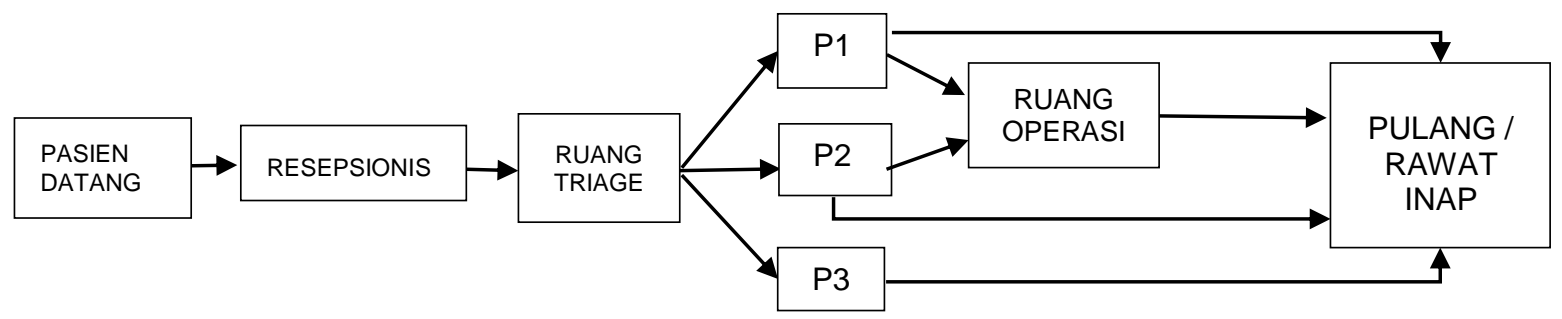

Gambar 2. Alur Sistem Pelayanan IGD

Bagian resepsionis ini pasien akan di data, Setelah dari resepsionis pasien menuju ruang triage, dimana semua pasien akan diperiksa dahulu kondisinya (tindakan pertama) dan diputuskan akan diberi tindakan sebagai pasien prioritas satu (P1), pasien prioritas dua (P2), atau pasien prioritas tiga (P3). Pada ruang triage petugas atau perawat bertanggung jawab untuk dapat segera mengambil keputusan (dengan respon time sam dengan nol), melakukan pengkajian resiko maupun pengkajian sosial, diagnosis pasien, menentukan pasien termasuk prioritas $\mathrm{P} 1, \mathrm{P} 2$, atau $\mathrm{P} 3$ dan merencanakan tindakan berdasarkan tingkat urgency.

Pembagian tindakan pasien berdasarkan prioritas bertujuan untuk menunjukkan apakah pasien dalam kondisi darurat, kritis, atau sangat kritis sehingga perlu dilakuakan operasi. Setelah dari ruang triage dan diketahui prioritas pasien, pasien dipindah ke ruang sesuai priori-tasnya. Selanjutnya, pasien prioritas satu, pasien prioritas dua, dan pasien prioritas tiga akan disebut dengan P1, P2, dan P3. Pasien yang tergolong P3 adalah pasien gawat darurat yang tidak memerlukan operasi, jadi pasien setelah diberi tindakan oleh dokter 
langsung bisa pulang. Sedangkan pasien di P1 dan P2 ada kemungkinan untuk dilakukan tindakan operasi atau setelah dari IGD menuju rawat inap. Sehingga dari P1 atau P2 dapat menuju ruang operasi. Pasien di P1 dan P2 terdapat dua kemungkinan setelah diberi tindakan yaitu yang pertama langsung pulang / rawat inap, yang kedua operasi lalu pulang / rawat inap. Jadi pelayanan pasien di IGD RSUD Kota $X$ berakhir apabila pasien pulang atau rawat inap, alur pelayanan IGD seperti ilustrasi pada Gambar 1.

Dari hasil analisa sistem pelayanan IGD RSUD Kota X, maka permasalahan ini dapat dimodelkan dengan timed petri net dengan menggunakan software Pipe dengan variabel-variabel sebagai berikut.

$P_{1}=$ Pasien anteri pendataan di resepsionis

$P_{2}=$ Idle / petugas resepsionis

$P_{3}=$ Pelayanan resepsionis

$P_{4} \quad=$ Pasien anteri di ruang triage

$P_{5}=$ Idle $/$ petugas di ruang triage

$P_{6}=$ Pemeriksaan di ruang triage

$P_{7}=$ Pasien anteri tindakan prioritas

$P_{8} \quad=$ Pemeriksaan pasien di P3

$P_{9} \quad=$ Pemeriksaan pasien di $\mathrm{P} 2$

$P_{10}=$ Pemeriksaan pasien di $\mathrm{P} 1$

$P_{11}=$ Pasien anteri di operasi

$P_{12}=$ Idle $/$ tim operasi

$P_{13}=$ Pasien di operasi

$P_{14}=$ Pasien di ruang pasca operasi

$P_{15}=$ Pasien keluar IGD
$T_{1} \quad=$ Pasien datang di IGD

$T_{2}=$ Mulai pelayanan resepsionis

$T_{3} \quad=$ Pasien menuju ruang triage

$T_{4} \quad=$ Mulai pemeriksaan di ruang triage

$T_{5}=$ Pasien menuju ruang tindakan

$T_{6} \quad=$ Mulai tindakan di P3

$T_{7} \quad=$ Selesai tindakan di P3

$T_{8} \quad=$ Mulai tindakan di P2

$T_{9} \quad=$ Selesai tindakan di P2

$T_{10}=$ Pasien P2 menuju ruang operasi

$T_{11}=$ Mulai tindakan di P1

$T_{12}=$ Pasien $\mathrm{P} 1$ menuju ruang operasi

$T_{13}=$ selesai tindakan di $\mathrm{P} 1$

$T_{14}=$ Pasien mulai di operasi

$T_{15}=$ Pasien selesai di operasi

$T_{16}=$ Selesai pelayanan di IGD

$T_{17}=$ Pasien pulang $/$ rawat inap

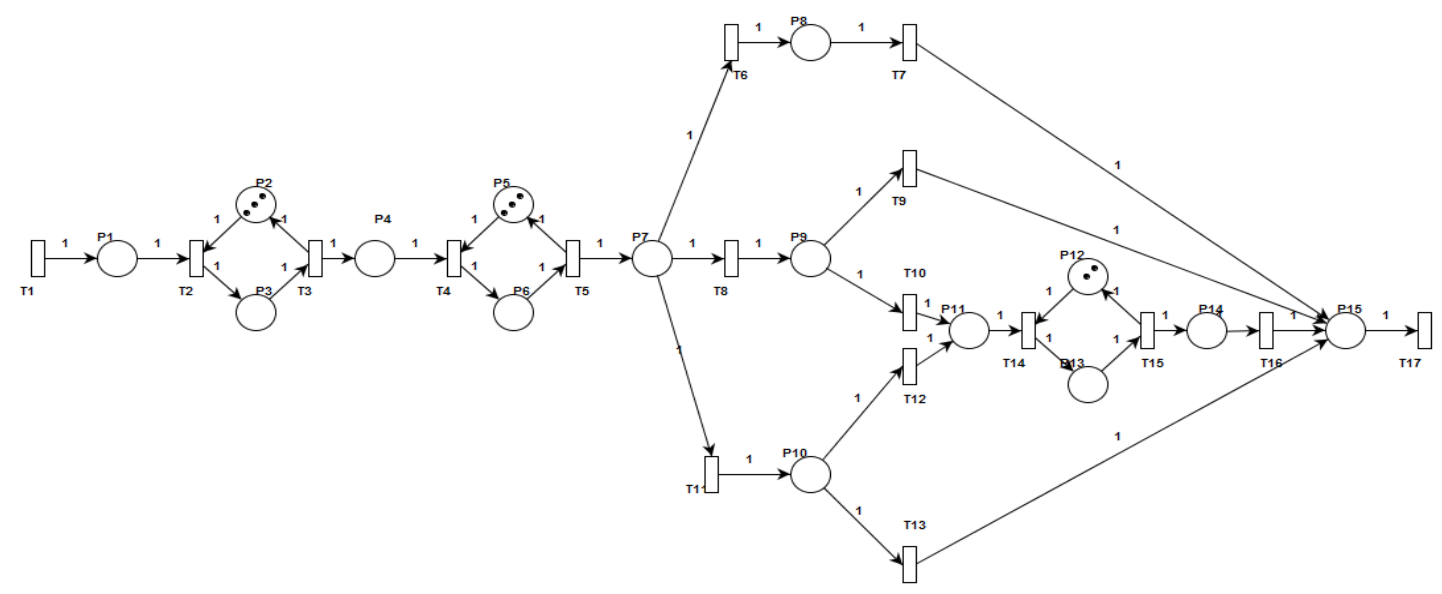

Gambar 3. Petri net Sistem Pelayanan IGD RSUD Kota X

Pada Gambar 3 diperlihatkan terdapat transisi $T_{1}$ yang selalu enabled, dimana $T_{1}$ merupakan saat pasien datang ke IGD, karena $T_{1}$ enabled maka $T_{1}$ dapat difire, apabila 
transisi $T_{1}$ melakukan proses difire maka mengakibatkan token akan selalu bertambah pada place $P_{1}$. Jika sudah terdapat token pada $P_{1}$ selanjutnya $T_{2}$ dapat difire apabila ada token idle yang tersedia. Idle berarti server tidak sibuk dengan kata lain terdapat petugas yang siap melayani, kasus ini berlaku juga pada $T_{4}$ dan $T_{14}$ dapat difire apabila terdapat token pada place sebelumnya dan token idle tersedia. Sedangkan untuk $T_{3}$ akan difire apabila terdapat token pada $P_{3}$, proses yang sama berlaku pada transisi dan place selanjutnya.

Petri net dapat direpresentasikan dalam bentuk matriks, yaitu matriks forward incidence dan backward incidence, dimana keduanya merupakan bagian dari matriks incidence. Bobot arc yang menghubungkan transisi ke place berfungsi sebagai elemen matriks forward incedence, sedangkan elemen matriks backward incidence adalah bobot arc yang menghubungkan place ke transisi. Berdasarkan model petri net pada Gambar 3 terdapat 15 place dan 17 transisi, sehingga matriks akan memiliki banyak baris $(n)=15$ dan banyaknya kolom $(m)=17$. Sehingga matriks-matriks yang terbentuk memiliki ordo $15 \times 17$ dengan representasi sebagai berikut.

Matriks backward incidence $\left(A_{b}\right)$

$$
\boldsymbol{A}_{\boldsymbol{b}}=\left[\begin{array}{lllllllllllllllll}
0 & 1 & 0 & 0 & 0 & 0 & 0 & 0 & 0 & 0 & 0 & 0 & 0 & 0 & 0 & 0 & 0 \\
0 & 1 & 0 & 0 & 0 & 0 & 0 & 0 & 0 & 0 & 0 & 0 & 0 & 0 & 0 & 0 & 0 \\
0 & 0 & 1 & 0 & 0 & 0 & 0 & 0 & 0 & 0 & 0 & 0 & 0 & 0 & 0 & 0 & 0 \\
0 & 0 & 0 & 1 & 0 & 0 & 0 & 0 & 0 & 0 & 0 & 0 & 0 & 0 & 0 & 0 & 0 \\
0 & 0 & 0 & 1 & 0 & 0 & 0 & 0 & 0 & 0 & 0 & 0 & 0 & 0 & 0 & 0 & 0 \\
0 & 0 & 0 & 0 & 1 & 0 & 0 & 0 & 0 & 0 & 0 & 0 & 0 & 0 & 0 & 0 & 0 \\
0 & 0 & 0 & 0 & 0 & 1 & 0 & 1 & 0 & 0 & 1 & 0 & 0 & 0 & 0 & 0 & 0 \\
0 & 0 & 0 & 0 & 0 & 0 & 1 & 0 & 0 & 0 & 0 & 0 & 0 & 0 & 0 & 0 & 0 \\
0 & 0 & 0 & 0 & 0 & 0 & 0 & 0 & 1 & 1 & 0 & 0 & 0 & 0 & 0 & 0 & 0 \\
0 & 0 & 0 & 0 & 0 & 0 & 0 & 0 & 0 & 0 & 0 & 1 & 1 & 0 & 0 & 0 & 0 \\
0 & 0 & 0 & 0 & 0 & 0 & 0 & 0 & 0 & 0 & 0 & 0 & 0 & 1 & 0 & 0 & 0 \\
0 & 0 & 0 & 0 & 0 & 0 & 0 & 0 & 0 & 0 & 0 & 0 & 0 & 1 & 0 & 0 & 0 \\
0 & 0 & 0 & 0 & 0 & 0 & 0 & 0 & 0 & 0 & 0 & 0 & 0 & 0 & 1 & 0 & 0 \\
0 & 0 & 0 & 0 & 0 & 0 & 0 & 0 & 0 & 0 & 0 & 0 & 0 & 0 & 0 & 1 & 0 \\
0 & 0 & 0 & 0 & 0 & 0 & 0 & 0 & 0 & 0 & 0 & 0 & 0 & 0 & 0 & 0 & 1
\end{array}\right]
$$

Matriks forward incidence $\left(A_{f}\right)$ 


$$
\boldsymbol{A}_{\boldsymbol{f}}=\left[\begin{array}{lllllllllllllllll}
1 & 0 & 0 & 0 & 0 & 0 & 0 & 0 & 0 & 0 & 0 & 0 & 0 & 0 & 0 & 0 & 0 \\
0 & 0 & 1 & 0 & 0 & 0 & 0 & 0 & 0 & 0 & 0 & 0 & 0 & 0 & 0 & 0 & 0 \\
0 & 1 & 0 & 0 & 0 & 0 & 0 & 0 & 0 & 0 & 0 & 0 & 0 & 0 & 0 & 0 & 0 \\
0 & 0 & 1 & 0 & 0 & 0 & 0 & 0 & 0 & 0 & 0 & 0 & 0 & 0 & 0 & 0 & 0 \\
0 & 0 & 0 & 0 & 1 & 0 & 0 & 0 & 0 & 0 & 0 & 0 & 0 & 0 & 0 & 0 & 0 \\
0 & 0 & 0 & 1 & 0 & 0 & 0 & 0 & 0 & 0 & 0 & 0 & 0 & 0 & 0 & 0 & 0 \\
0 & 0 & 0 & 0 & 1 & 0 & 0 & 0 & 0 & 0 & 0 & 0 & 0 & 0 & 0 & 0 & 0 \\
0 & 0 & 0 & 0 & 0 & 1 & 0 & 0 & 0 & 0 & 0 & 0 & 0 & 0 & 0 & 0 & 0 \\
0 & 0 & 0 & 0 & 0 & 0 & 0 & 1 & 0 & 0 & 0 & 0 & 0 & 0 & 0 & 0 & 0 \\
0 & 0 & 0 & 0 & 0 & 0 & 0 & 0 & 0 & 0 & 1 & 0 & 0 & 0 & 0 & 0 & 0 \\
0 & 0 & 0 & 0 & 0 & 0 & 0 & 0 & 0 & 1 & 0 & 1 & 0 & 0 & 0 & 0 & 0 \\
0 & 0 & 0 & 0 & 0 & 0 & 0 & 0 & 0 & 0 & 0 & 0 & 0 & 0 & 1 & 0 & 0 \\
0 & 0 & 0 & 0 & 0 & 0 & 0 & 0 & 0 & 0 & 0 & 0 & 0 & 1 & 0 & 0 & 0 \\
0 & 0 & 0 & 0 & 0 & 0 & 0 & 0 & 0 & 0 & 0 & 0 & 0 & 0 & 1 & 0 & 0 \\
0 & 0 & 0 & 0 & 0 & 0 & 1 & 0 & 1 & 0 & 0 & 0 & 1 & 0 & 0 & 1 & 0
\end{array}\right]
$$

Matriks incidence $(A)$

$$
\begin{aligned}
& A=A_{f}-A_{b} \\
& =\left[\begin{array}{ccccccccccccccccc}
1 & -1 & 0 & 0 & 0 & 0 & 0 & 0 & 0 & 0 & 0 & 0 & 0 & 0 & 0 & 0 & 0 \\
0 & -1 & 1 & 0 & 0 & 0 & 0 & 0 & 0 & 0 & 0 & 0 & 0 & 0 & 0 & 0 & 0 \\
0 & 1 & -1 & 0 & 0 & 0 & 0 & 0 & 0 & 0 & 0 & 0 & 0 & 0 & 0 & 0 & 0 \\
0 & 0 & 1 & -1 & 0 & 0 & 0 & 0 & 0 & 0 & 0 & 0 & 0 & 0 & 0 & 0 & 0 \\
0 & 0 & 0 & -1 & 1 & 0 & 0 & 0 & 0 & 0 & 0 & 0 & 0 & 0 & 0 & 0 & 0 \\
0 & 0 & 0 & 1 & -1 & 0 & 0 & 0 & 0 & 0 & 0 & 0 & 0 & 0 & 0 & 0 & 0 \\
0 & 0 & 0 & 0 & 1 & -1 & 0 & -1 & 0 & 0 & -1 & 0 & 0 & 0 & 0 & 0 & 0 \\
0 & 0 & 0 & 0 & 0 & 1 & -1 & 0 & 0 & 0 & 0 & 0 & 0 & 0 & 0 & 0 & 0 \\
0 & 0 & 0 & 0 & 0 & 0 & 0 & 1 & -1 & -1 & 0 & 0 & 0 & 0 & 0 & 0 & 0 \\
0 & 0 & 0 & 0 & 0 & 0 & 0 & 0 & 0 & 0 & 1 & -1 & -1 & 0 & 0 & 0 & 0 \\
0 & 0 & 0 & 0 & 0 & 0 & 0 & 0 & 0 & 1 & 0 & 1 & 0 & -1 & 0 & 0 & 0 \\
0 & 0 & 0 & 0 & 0 & 0 & 0 & 0 & 0 & 0 & 0 & 0 & 0 & -1 & 1 & 0 & 0 \\
0 & 0 & 0 & 0 & 0 & 0 & 0 & 0 & 0 & 0 & 0 & 0 & 0 & 1 & -1 & 0 & 0 \\
0 & 0 & 0 & 0 & 0 & 0 & 0 & 0 & 0 & 0 & 0 & 0 & 0 & 0 & 1 & -1 & 0 \\
0 & 0 & 0 & 0 & 0 & 1 & 0 & 1 & 0 & 0 & 0 & 1 & 0 & 0 & 0 & 1 & -1
\end{array}\right]
\end{aligned}
$$

Berdasarkan model petri net sebelumnya didapatkan matriks-matriks di atas. Matriks backward incedence dan matriks forward incidence memiliki elemen matriks yang bernilai 0 dan 1 yang berarti apabila ada arc yang memhubungkan transisi ke place atau place ke transisi elemen matriks bernilai 1, sedangkan 0 artinya antara place dan transisi tidak ada arc yang menghubungkan. Selanjutnya dengan matriks incidence elemen-elemennya bernilai 0,1 , dan -1 diperoleh dari hasil pengurangan antara matriks backward incedence dan matriks forward incidence. Nilai dari elemen-elemen matriks dapat berbeda dan bervariasi tergantung dari bobot arc yang ada pada petri net. Selanjutnya, kolom matriks backward incedence dapat digunakan untuk menentukan transisi yang enable. Kita juga 
dapat menentukan keadaan berikutnya dengan menggunakan matrik incidence. Berdasarkan hasil penelitian ini kita dapat mengetahui model petri net apabila diketahui matriks forward incidence, backward incidence,dan matriks incidence.

\section{SIMPULAN}

Pembelajaran matematika dapat dibuat menarik dengan memberikan simulasi dan contoh yang nyata pada kehidupan. Diharapkan pada penelitian selanjutnya permasalahan yang dimodelkan dapat lebih berkembang dan beraneka ragam. Penelitian ini juga dapat dikembangkan untuk mengetahui berapa lama waktu antrian dengan menggunakan Petri net dengan aljabar maxplus.

\section{DAFTAR PUSTAKA}

Cassandras, C. G., \& Lafortune, S. 2008. Introduction to Discrete Event Systems Second Edition. New York: Springer.

Komsiyah, S. 2012). Model petri net tak berwaktu pada sistem produksi (batch plant) dan simulasinya dengan PIPE2. Jurnal Mat Stat, 12(2): 152-164.

Murata, T. 1989. Petri Nets: Properties, Analysis and Applications. Proceding of The IEEE, (hal. 541-580).

Mustofani, D. 2018. Model Antrian Pelayanan Farmasi Menggunakan Petrinet dan Aljabar Max-Plus. JMPM: Jurnal Matematika dan Pendidikan Matematika, 3(1), 33-43.

Pertiwi, R., I. (2016). Verifikasi Formal Petri Net dengan Counter pada Sistem Inventori. Tesis, Fakultas MIPA: Institut Teknologi Sepuluh Nopember.

Subiono. 2015. Aljabar Min-Max Plus dan Terapannya. Institut Teknologi Sepuluh Nopember. Surabaya.

Subiono, Nurwan. 2014. Model Petri Net Antrian Klinik Kesehatan Serta Kajian Dalam Aljabar Max Plus, Jurnal Matematika FMIPA ITS.

Winarni, W. (2011). Penjadwalan Jalur Bus dalam Kota dengan Model Petrinet dan Aljabar Max-Plus (Studi Kasus Busway TransJakarta). Cauchy, 1(4), 192-206 